九州大学学術情報リポジトリ

Kyushu University Institutional Repository

Effect of host age and size on offspring sex ratio in the pupal parasitoid Pimpla (=Coccygomimus) luctuosa (Hymenoptera: Ichneumonidae)

Ueno, Takatoshi

Faculty of Agriculture, Kyushu University

https://doi.org/10.5109/4653

出版情報：九州大学大学院農学研究院紀要. 50 (2)，pp. 399-405，2005-10-01. Faculty of Agriculture, Kyushu University

バージョン：

権利関係 : 


\title{
Effect of host age and size on offspring sex ratio in the pupal parasitoid Pimpla (=Coccygomimus) luctuosa (Hymenoptera: Ichneumonidae)
}

\author{
Takatoshi UENO* \\ Institute of Biological Control, Faculty of Agriculture, Kyushu University, \\ Fukuoka 812-8581, Japan \\ (Received June 29, 2005 and accepted July 26, 2005)
}

\begin{abstract}
Host age is an important factor affecting the offspring sex ratio of egg and larval parasitoid wasps. Relatively few studies have investigated the effect of host age on the offspring sex ratio in pupal parasitoid wasps. The current study was undertaken to assess whether the age of host pupae could influence the offspring sex ratio of the pupal parasitoid Pimpla luctuosa Smith (Hymenoptera: Ichneumonidae: Pimplinae). Test female wasps were simultaneously provided with young and old host pupae of different sizes, and the effects of host age, size and the interaction between the two factors were examined. Both host age and size significantly affected the offspring sex ratio of $P$. luctuosa. The proportions of female offspring produced from hosts increased with host size in both host age classes. Old hosts produced fewer female offspring than did young hosts, however. No significant interactions were detected between host age and size. The results indicated that female P. luctuosa responded hosts of different sizes and ages by changing the offspring sex ratio. Besides, the mean sex ratios were highly male-biased, regardless of host age. The sex allocation strategy in P. luctuosa is discussed. Factors causing male-biased sex ratios are also discussed.
\end{abstract}

\section{INTRODUCTION}

Most parasitoid wasps have a haplo-diploid sex determination system (Flanders, 1956; Quicke, 1997). This system allows the ovipositing female wasp to control the sex of her eggs by controlling sperm access to eggs. In fact, the adult females of many parasitoid species respond to a number of environmental variables by changing the offspring sex ratio. Among the variables, host type (e.g. host size, age, and species) is one of the most important factors influencing the offspring sex ratio of parasitoid wasps (King, 1987; Godfray, 1994; Heimpel and Lundgren, 2000).

The relationships between offspring sex ratio and host type have been investigated for many parasitoid wasps. Host size is accepted as a major factor affecting their offspring sex ratios (King, 1993). A correlation between host size and offspring sex ratio has commonly been demonstrated for solitary parasitoids (e.g. Charnov et al., 1981; King, 1993; Ueno and Tanaka, 1997; Ode and Heinz, 2002). The general trend is that the proportion of female wasps emerging from large hosts is higher than that from small hosts.

Host age is another factor that has a significant impact on parasitoid sex ratios (King, 1987; Godfray, 1994). Host age may positively correlate to host size when host insects are larval stages. The relationships between host age and offspring sex ratio for larval parasitoids can simply reflect host-size effects on the sex ratio. The offspring sex ratio in

\footnotetext{
* Corresponding author (E-mail: ueno@grt.kyushu-u.ac.jp)
} 
some pupal parasitoids is also affected by the age of host pupae; older host pupae produce more male wasp offspring (King, 1990; Ueno, 1997). In this case, however, host age is not associated with host size because the size of host pupae does not change with pupal age, and hence the host age effect on the offspring sex ratio is unlikely to result from differences in host size. Thus, host size and age can independently affect the offspring sex ratio in pupal parasitoids.

Knowing what factors influence parasitoid sex ratios is important for the practical applications of parasitoids in biological control (Caltagirone, 1981; Heimpel and Lundgren, 2000). Although many parasitoids can usually attack a range of hosts differing in size, provision of small hosts can cause a male-biased sex ratio, resulting in a reduction of mass rearing efficiency (Heimpel and Lundgren, 2000; Ode and Heinz, 2002). This is because offspring sex ratios depend on the size of hosts. Also, provision of fresh hosts may be required to improve parasitoid rearing efficiency if female parasitoids respond to an increase in host age by producing an increased proportion of male offspring.

Thus, investigation of the effects of host size and age on parasitoid sex ratio is important in biological control. Relatively few studies have investigated host age effects on the offspring sex ratio in pupal parasitoids. In addition, interactive effects between host size and age on parasitoid sex ratio are not known. The primary aim of the present study is to assess the effect of host age and size on the offspring sex ratio in the pupal parasitoid wasp Pimpla (=Coccygomimus) luctuosa Smith (Hymenoptera: Ichneumonidae: Pimplinae).

Pimpla luctuosa is a large solitary pupal endoparasitoid, distributed widely in Japan and other parts of East Asia (Townes et al., 1965; Yasumatsu and Watanabe, 1965). It is commonly found in a variety of agricultural fields, and is recorded as a parasitoid of many lepidopteran pests (Townes et al., 1965; Yasumatsu and Watanabe, 1965). P. luctuosa may have a significant impact on pest insect populations. The biological characteristics and life history of $P$. luctuosa are not fully understood, however. No study has examined the relationship between host age and offspring sex ratio in this parasitoid. Accordingly, experiments were conducted to examine this relationship in the present study. Based on the results, factors influencing the sex ratio of $P$. luctuosa were discussed.

\section{MATERIALS AND METHODS}

\section{Parasitoid and host}

All experiments were conducted with larboratory populations of $P$. luctuosa and a laboratory host, Galleria mellonella. The colony of $P$. luctuosa was originated from adult wasps collected in Kobe, Hyogo Prefecture. Female wasps used in the experiments were F2 or F3 generations.

\section{Sex-ratio experiments}

Twelve newly emerged female wasps after mating were placed individually in plastic containers $(10 \mathrm{~cm}$ in diameter, $4.5 \mathrm{~cm}$ in height), together with tissue paper saturated with diluted honey. The tissue paper was replaced twice a week thereafter in order to provide the wasps with fresh food. The containers were kept at $20 \pm 1^{\circ} \mathrm{C}$. As a pre-experimental treatment, females were presented with two host fresh cocoons for 
three days on a daily basis.

Host cocoons of variable sizes were divided into two age classes: 1-3 days old and 5-7 days old hosts. A random mixture of these two classes was presented to individual test females. Between day 5 and day 16 after wasp emergence, hosts were individually offered to each female wasp, and her response to the hosts was directly observed under a binocular stereoscope. During oviposion, it is possible to see an egg passing through the base of the ovipositor (Ueno, 1995), and oviposition on the hosts can readily be confirmed. Care was taken to avoid superparasitism and host feeding. This procedure was repeated 3-4 times per female every other day; thus, 3-4 hosts were presented to each female during the experimental day. This was because female $P$. luctuosa carried a relatively small number of mature eggs at any one time.

Hosts were removed immediately after oviposition and were weighed. All parasitized hosts were kept at $25 \pm 0.5^{\circ} \mathrm{C}, 60-70 \% \mathrm{RH}$, and a photoperiod of $16: 8$ (L:D) $\mathrm{h}$, until parasitoid emergence. When wasp offspring emerged, the sexes of the offspring were recorded. Statistical treatments were made with the aid of JMP (SAS Institute, 2001).

\section{RESULTS}

In total, 91 wasp offspring were obtained in the experiment. A multiple logistic regression analysis was performed to assess the effects of host weight, age and the interaction between the two factors on the offspring sex ratio in $P$. luctuosa. The whole model was significant $\left(\chi^{2}=17.70, \mathrm{df}=3, P=0.0013\right)$. The analysis showed that both host weight and age had significant effects on the offspring sex ratio in $P$. luctuosa (Table 1).

Table 1. The result of a multiple logistic regression analysis for offspring sex ratio of Pimpla luctuosa

\begin{tabular}{lccc}
\hline Factors & df & Wald $^{2}$ & P values \\
\hline Host age & 1 & 4.21 & 0.040 \\
Host weight & 1 & 5.27 & 0.022 \\
Interaction & 1 & 0.02 & 0.89 \\
\hline
\end{tabular}

The percentages of female offspring produced were higher in young host pupae than old host pupae (Fig. 1), and the difference was significant (Chi-squared test; $\chi^{2}=6.36$, $\mathrm{df}=1, P=0.012$ ). The sex ratios of wasp offspring produced from young and old hosts were $31.0 \%$ and $9.1 \%$, respectively, and were significantly male-biased (Binomial test; $\chi^{2}$ $=8.56, \mathrm{df}=1, P=0.003$ for young hosts; $\chi^{2}=25.64, \mathrm{df}=1, P<0.0001$ for old hosts).

To examine the relationships between host weight and offspring sex ratio, simple logistic regression analyses were made for each host age class. Significant relationships were detected in both host age classes, and the proportions of female offspring produced increased with increasing host weights (Fig. $2 \mathrm{a}, \mathrm{b} ; \chi^{2}=6.95, \mathrm{df}=1, P=0.0008$ for young hosts; $\chi^{2}=5.16, \mathrm{df}=1, P=0.023$ for old hosts). 


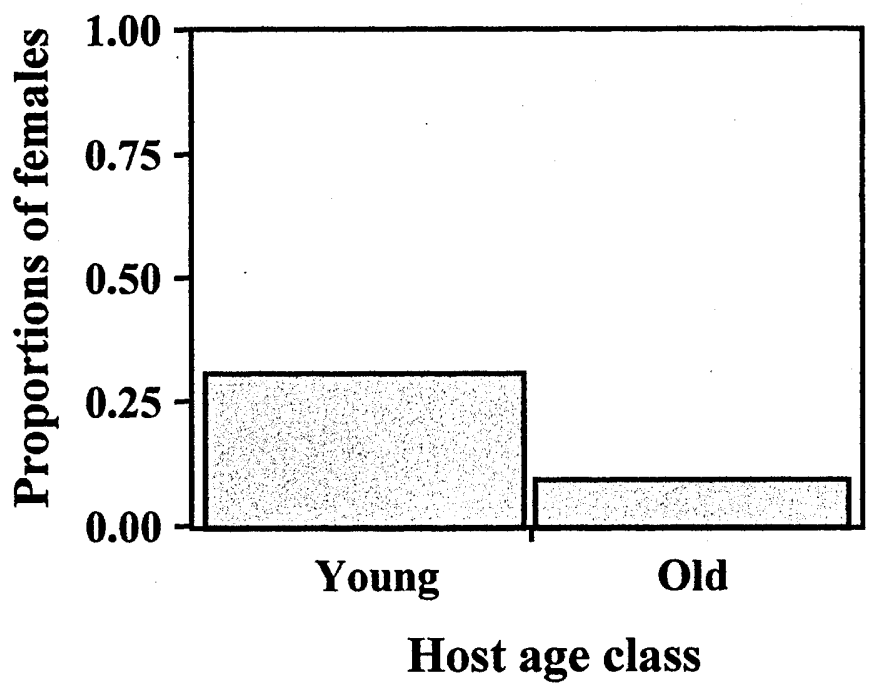

Fig. 1. The effect of host pupal age on offspring sex ratio of Pimpla luctuosa. The sex ratios differ between the groups (Chi-squared test; $P<0.05$ ). Also, the sex ratios are highly male-baised for both groups (binomial test; $P<0.001$ ).

\section{DISCUSSION}

The present study showed that the offspring sex ratios of $P$. luctuosa differed between young and old host pupae. Like other members of Pimplini, $P$. luctuosa is demonstrated to control the offspring sex ratio in response to host size by controlling sperm access to eggs (Ueno and Tanaka; 1997; Ueno, 1998; see also Fig. 2). Likewise, female $P$. luctuosa appears to change the offspring sex ratio in response to hosts of different ages.

Sex allocation control in response to host age can be an adaptive behavior to cope with change in host quality. For a number of pupal parasitoids, host age is a determinant for host suitability (e.g. Fuester et al., 1986; Hailemichael et al., 1994; Ueno, 1997; Hunsi et al., 2001). In those parasitoids, old hosts are generally of poorer quality than young hosts are; the survival of wasp offspring is reduced in old hosts. In addition, offspring size and developmental rate can decrease with increasing host pupal age. Likewise, host suitability evidently decreases with host pupal age in P. luctuosa (Ueno, 2004).

The present study gave evidence that female offspring was more likely to emerge from larger hosts regardless of host age classes examined (Fig. 2). The sex ratio of parasitoid wasps is commonly affected by the amount of resources that is available to the developing larvae (e.g. Charnov et al., 1981; King, 1993; Ueno and Tanaka, 1997). Host size, which reflects the amount of host resources, is a major factor that positively relates to the proportion of female offspring produced from hosts (King, 1987; Godfray, 1994; Quicke, 1997). This held true for P. luctuosa. 

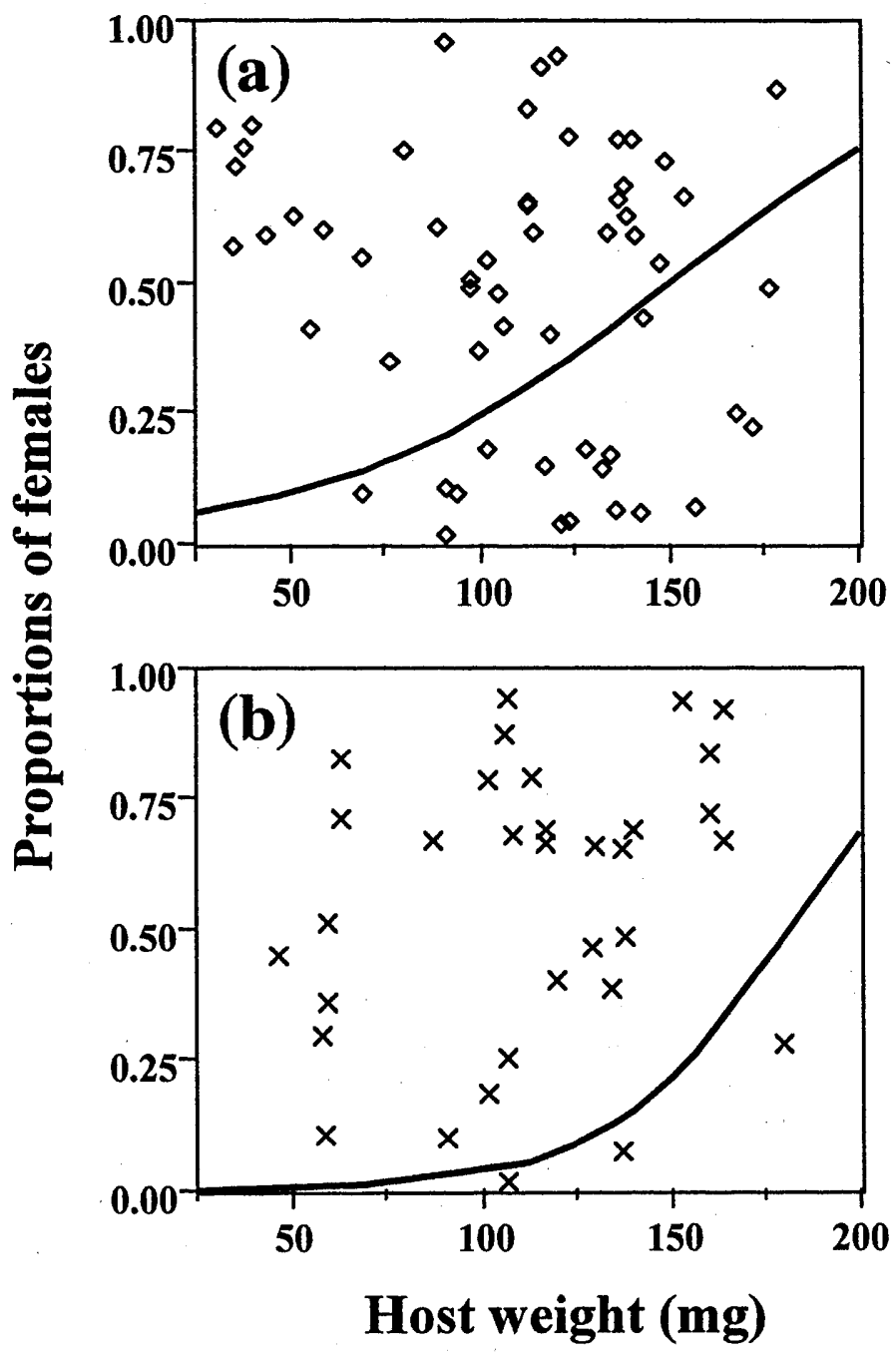

Fig. 2. The relationships between host size and offspring sex ratio of Pimpla luctuosa in young host pupae (a) and old host pupae (b). The regressions are significant (logistic regression analyses; $P<0.05)$.

Previous studies with $P$. luctuosa have shown that host-size dependent sex ratio is not the consequence of differential mortality between the sexes during the immature stage (Ueno, 1998); the sex ratio change with host size is due to maternal control. Such sex ratio control is theoretically considered adaptive if host size differentially affects the reproductive success of male versus female offspring (Charnov et al., 1981; King, 1993). 
There is no experimental evidence for the presence of differential effects of host size on males versus females in $P$. luctuosa. Therefore, the adaptiveness of sex ratio control in $P$. luctuosa remains to be addressed in future studies.

Host-age dependent sex ratio in $P$. luctuosa can also be an adaptive behavior in response to change in amount of host resources. During the pupal stage, larval tissue is reconstructed dramatically to adult tissue with increasing pupal ages. Adult tissue newly constructed is sclerotized in particular around the pupal body surface. Developing larva may have difficulty to digest such sclerotized tissues. Hence, the amount of resources available for the developing larva should be fewer in older host pupae.

Although it is evident that $P$. luctuosa can assess the quality of hosts and control the offspring sex ratio accordingly, it remains unclear what cues the female wasp uses upon host quality assessment. It will be possible for a female wasp to assess the amount of host resources by measuring external host dimensions when she oviposits on hosts of different sizes. P. luctuosa may use physical cues upon host size estimation.

In contrast, the mechanisms of host age assessment would not be simple. In the present study, $P$. luctuosa was allowed to attack cocooned hosts. The size and morphology of the cocoons do not change with host age. Thus, host pupal age is unlikely to be associated with changes in external host dimensions. This suggests that female $P$. luctuosa can detect changes associated with host age by cues other than external dimensions. A likely cue is.chemical changes within host pupae, which may be detected with the ovipositor. Alternatively, $P$. luctuosa may use host odors to recognize host age.

The present study also showed that the offspring sex ratio of $P$. luctuosa was highly male-biased. Although $P$. luctuosa evidently attacks a variety of lepidopteran hosts in nature, host species recorded appears to be restricted to relatively large Lepidoptera, such as noctuids (Townes et al., 1965; Yasumatsu and Watanabe, 1965). These natural hosts are much larger than the laboratory host, G. mellonella. Although $P$. luctuosa modifies the offspring sex ratio in response to host size, $G$. mellonella may be so small that it cannot attain equal sex ratios. Given this, $G$. mellonella would not be a suitable laboratory host for mass rearing of $P$. luctuosa, though this host is highly suitable in that offspring production is high and that the mass rearing is easy (Ueno, 2004). Thus, alternative laboratory hosts will be required to improve the sex ratio of $P$. luctuosa.

\section{ACKNOWLEDGEMENTS}

This work was partly supported by grants from the Ministry of Education, Sciences, Sports and Culture of Japan (No. 13760039 and 15208007).

\section{REFERENCES}

Caltagirone, L. E. 1981 Landmark examples in classical biological control. Annu. Rev. Entomol., 19: 213-232

Charnov, E. L., R. L. Los-den Hartogh, W. T. Jones and J. van den Assem 1981 Sex ratio evolution in a variable environment. Nature, 289: 27-33

Flanders, S. E. 1956 The mechanism of sex-ratio regulation in the parasitic Hymenoptera. Insect. Soc., 3: $325-334$

Fuester, R. W., P. B. Taylor and A. Eisenberg 1989 Suitability of prepupae and pupae of the Gypsy moth (Lepidoptera: Lymantriidae) as hosts of Coccygomimus disparis (Hymenotpera: Ichneumonidae). 
Environ. Entomol., 18: 338-341

Godfray, H. C. J. 1994 Parasitoids: Behavioral and evolutionary ecology. Princeton University Press, Princeton

Hailemichael, Y., J. W. Smith Jr. and R. N. Wiedenmann 1994 Host-finding behavior, host acceptance, and host suitability of the parasite Xanthopimpla stemmator. Entomol. Exp. Appl., 71: 155-166

Heimpel, G. E. and J. G. Lundgren 2000 Sex ratios of commercially reared biological control agents. Biol. Cont., 19: 77-93

Husni, Y. Kainoh and H. Honda 2001 Effects of host pupal age on host preference and host suitability in Brachymeria lasus (Hymenoptera: Chalciddiae). Appl. Entomol. Zool., 36: 97-102

JMP 2001 JMP version 4.0. SAS Institute Inc., Cary, NC

King, B. H. 1987 Offspring sex ratios in parasitoid wasps. Q. Rev. Biol., 62: 367-396

King, B. H. 1990 Sex ratio manipulation by the parasitoid wasp Spalangia cameroni in response to host age: a test of the host-size model. Evol. Ecol., 4: 149-156

King, B. H. 1993 Sex ratio manipulation by parasitoid wasps. In Wrensch, D. L., Ebbert, M. (Eds.), "Evolution and Diversity of Sex Ratio in Insects and Mites", Chapman \& Hall, New York, pp 418-441

Ode, P. J. and K. M. Heinz 2002 Host-size-dependent sex ratio theory and improving mass-reared parasitoid sex ratios. Biol. Cont., 24: 31-41

Quicke, D. L. J. 1997 Parasitic Wasps. Chapman \& Hall, London

Townes, H., S. Momoi and M. Townes 1965 A catalogue and reclassification of the Easterm Palearctic Ichneumonidae. Memoris of The American Entomological Institute No. 5

Ueno, T. 1995 Abdominal tip movements during oviposition by two parasitoids (Hymenoptera Ichneumonidae) as an index of predicting the sex of depositing eggs. Appl. Entomol. Zool., 30: 588-590

Ueno, T. 1997 Host age preference and sex allocation in the pupal parasitoid Itoplectis naranyae (Hyemoptera: Ichneumonidae). Ann. Entomol. Soc. Am., 90: 640-645

Ueno, T. 1998 Sex allocation by a parasitoid wasp (Hymenoptera: Ichneumonidae) to different host species: a question for the mechanism of host size estimation. J. Insect Behav., 11: 811-821

Ueno, T. 2004 Offspring performance in the pupal parasitoid Pimpla (=Coccygomimus) luctuosa (Hymenoptera: Ichneumonidae) as influenced by host age and size. J. Fac. Agric., Kyushu Univ., 49: 321-329

Ueno, T. and T. Tanaka 1997 Comparison of primary and secondary sex ratios in parasitoid wasps using a method for observing chromosomes. Entomol. Exp. Appl., 82: 105-108

Yasumatsu, K. and C. Watanabe 1965 A tentative catalogue of insect natural enemies of injurious insects in Japan. Part 2. Host parasite-predator catalogue. Entomol. Lab., Fac. Agric., Kyushu Univ. Press, Fukuoka 